\title{
Environmental Sustainability In Post-Conflict Countries: Insights For Rural Colombia
}

\author{
Suarez Agudelo, Andres; Arias Arevalo, Paola Andrea; Martínez Mera, Eliana \\ Andrea.
}

\begin{abstract}
Post-conflict countries (PCC) guide their priorities toward restoration of socioeconomic conditions and relegate sustainability objectives to the background. With the aim to provide insights for the current discussion on rural environmental sustainability in today's post-conflict Colombia, we analyzed the environmental dynamics of seven PCC. We found that (1) deforestation and land use conflicts were frequent impacts in both conflict and post-conflict scenarios, that (2) return of displaced population, the infectiveness of land use planning, and the dependence on the primary sector were frequent drivers of environmental change; and that (3) natural resources extraction tends to be intensified in post-conflict period. We discuss these findings in light of the current environmental problems of Colombia and the post-conflict environmental challenges. We conclude that in order to ensure environmental sustainability in post-conflict scenario, Colombia should act on structural aspects that go beyond the environmental objectives proposed in the peace agreement between the government and FARC: strengthening environmental institutions, integrating long-term environmental objectives across all sectors, and deintensifying the dependence of the economy in the extractive sector.
\end{abstract}

\section{Keywords}

Armed Conflicts; Colombia; Environmental Impacts; Environmental Sustainability; Natural Resources Extraction; Post-Conflict Countries; Social Metabolism. 